\title{
Local and geographic variation in the defensive chemistry of a West Indian gorgonian coral (Briareum asbestinum)
}

\author{
C. Drew Harvell ${ }^{1}$, William Fenical ${ }^{2}$, Vassilios Roussis ${ }^{2}$, Jennifer L. Ruesink ${ }^{1}$, \\ Catherine C. Griggs ${ }^{1}$, Charles H. Greene ${ }^{1}$
}

${ }^{1}$ Section of Ecology and Systematics, Cornell University, Ithaca, New York 14853, USA

${ }^{2}$ Scripps Institution of Oceanography, La Jolla, California 92093-0228, USA

\begin{abstract}
We sampled the between-colony and between-habitat variation in defensive chemistry of colonies of Briareum asbestinum, one of the most ubiquitous and chemically deterrent of the West Indian gorgonians. The basis of deterrence appears to reside in a diverse complement of 5 to 15 briarane and asbestinane diterpenoids found in individual colonies. Variation in chemistry of colonies is extensive throughout the Bahamas and the Virgin Islands: the complement of compounds is slightly different at each site in the Bahamas and colonies from all the Bahamian sites are distinct from those at the St. Croix (US Virgin Islands) site. St. Croix colonies not only differ in their composition of compounds, but also have fewer major diterpenoids than colonies from shallow water sites in the Bahamas. The shallow St. Croix extracts also differ in being dominated by asbestinanes instead of briaranes as in the Bahamas. The qualitative chemistry of colonies also varies locally between depths near San Salvador and Chub Cay, 2 islands in the Bahamas. At both sites, the ratio of briarane to asbestinane diterpenoids was higher in shallow ( 1 to $12 \mathrm{~m}$ ) water colonies than in deeper ones ( 25 to $40 \mathrm{~m}$ ). To determine whether the qualitative differences in chemistry between depths could be induced or were fixed colonies were transplanted from shallow to deep reefs in San Salvador. After 7 mo, newly grown tissue from transplanted colonies still retained the same shallow water diterpenes. This experiment suggests that the qualitative differences in chemistry observed with depth are fixed in adult colonies. We also sampled quantitative variation in colonies from St. Croix and the Bahamas. Although we expected higher levels of compounds in shallow colonies because both productivity and numbers of predators are higher in shallow waters, at both sites levels of compounds were higher in deeper waters. Briareum asbestinum is unusual in being heavily invested with a diversity of extremely deterrent diterpenoids. The outstanding feature of this chemical defense system is the qualitative variation in the chemistry of colonies from different habitats, which appears to be genetically fixed, raising the question of what selective agents maintain the variation in chemistry among different habitats.
\end{abstract}

\section{INTRODUCTION}

Patterns of geographic and more local between-habitat variation in secondary compounds have been welldocumented in terrestrial plants. Investigation of the causes of variation in traits across geographic and even very local clines (Antonovics 1976) has provided tremendous insight into relative factors favoring the evolution of particular traits. For example, cyanogenesis in Lotus corniculatus is more prevalent in southern European than in northern populations. The shift in chemical composition across geographic regions is thought to reflect conflicting selection pressures: the cyanogenic form is probably favored as a deterrent to herbivores throughout its range, but is selected against by low northern temperatures which cause cell damage and release the toxin into the plant tissues (Jones 1966,1972 ). Similarly, geographic variation in several monoterpenes of Ponderosa pine is correlated with past outbreaks of the destructive mountain pine beetle. Populations with a history of attack have a high frequency of trees containing limonene, which is toxic to the beetle (Sturgeon 1979). Sturgeon interprets the pattern as a consequence of selection for resistant trees 
surviving past outbreaks. These patterns and experimental evidence for processes underlying them have provided some of our most useful models of plantherbivore coevolution and yet they are all examples from terrestrial environments. Analyses of variation between localized populations have also been reported for secondary compounds from marine algae; algae from reef slope populations were dominated by the diterpene trialdehyde, halimedatrial, and algae from non-reef slope populations were dominated by the related, but less toxic compound, halimedatetraacetate. Although the causes and degree of heritability of the chemical shift are unknown, it is suggested to be maintained by predation since reef slopes were subject to more intense herbivory than non-slope populations and halimedatrial is a more deterrent compound (Paul \& Van Alstyne 1988)

Gorgonian soft corals are analogous to plants in a number of ecologically significant ways. As sessile modular, clonal organisms, they are architecturally and even functionally similar to plants (Harper 1981) However, instead of modular units composed of leaves, the unils are composed of small feeding polyps Because the tissues house symbiotic algae called zooxanthellae, the carbon budget of these corals is heavily dependent on photosynthate produced by their symbionts. As with terrestrial plants and marine algae, high allocation to chemical and structural defenses seems associated with a sessile architecture and inability to move away from predator-rich environments. Because of their functional similarity to plants, colonial marine invertebrates provide a useful functional analog for testing hypotheses about the evolution and function of such characters as secondary compounds. Gorgonians contain especially high levels of biologically active compounds which have been hypothesized to function against predators (Fenical 1982, Gerhart 1984, Bakus et al. 1986, Pawlik et al. 1987, Harvell \& Fenical 1989), competitors (Sammarco et al. 1983, 1987, Rittschoff et al. 1985, LaBarre et al. 1986), and microalgae as well as other fouling organisms (Targett et al. 1983; Bandurraga \& Fenical 1984, Bakus et al. 1986). The compounds are primarily terpenes and acetogenins, and several have been of biomedical significance due to their novel structures and unusual potential in the development of pharmaceuticals and agrichemical agents (see reviews by Tursch et al. 1978, Faulkner 1986, 1987, 1988, 1990). Despite a decade of intense interest in these compounds and over 100 papers describing the isolation of novel gorgonian compounds with potent biological activity, little has been reported defining within-and between-habitat variability in the levels and types of compounds from a single species. Even studies that have reported such variation did not investigate whether the differences were habitat-spe- cific induced effects or genetically fixed. This information is critical in understanding the past, and evaluating the future potential for the evolution of chemical defenses.

Briareum asbestinum (Pallas) is one of the most ubiquitous and geographically widespread of Caribbean gorgonians. The species is present in many shallow back reefs from Florida in the northwestern Caribbean to the southern Grenadine Islands in the southeastern Caribbean Sea (pers. obs.). B. asbestinum occurs in 2 distinct morphologies, either erect or encrusting; our samples from the Bahamas indicate that the erect form is genotypically distinct from the encrusting form (Brazeau \& Harvell unpubl.). We refer only to the erect form in this paper, which occupies an unusually wide habitat range, from protected to exposed shallow waters and from shallow $(3 \mathrm{~m}$ ) to quite deep reefs (40 m) at some sites (Bayer 1961). The form of the erect colony does not vary appreciably with geographic distance but is strikingly different with depth and exposure changes (West et al. in press). B. asbestinum propagates asexually both through clonal fragmentation and by runners (Lasker 1983), and sexually through the production of lecithotrophic eggs. The eggs are extruded through the polyps in a lunarphased event and retained on the colony surface, where they develop into larvae (Brazeau \& Lasker 1990). The larvae appear philopatric and drop close to their natal colony to metamorphose (Brazeau \& Lasker 1990, C.D.H. pers. obs.). Since dispersal is so limited, there is the potential for local selection regimes to shape populations into locally adapted assemblages.

Briareum asbestinum is also one of the most deterrent species identified in a survey of relative deterrencies of Caribbean gorgonians to a species of wrasse, Thalassoma bifasciatum (Pawlik et al. 1987, C.D.H. \& W.F. unpubl.). Although B. asbestinum, like other gorgonians, has calcium carbonate sclerites which can act as structural defenses (Harvell \& Suchanek 1987. Harvell et al. 1988, West et al. in press), the bulk of the deterrence to most vertebrate predators appears to be chemical (Pawlik et al. 1987). The secondary compounds of $B$. asbestinum are unusually diverse and consist mainly of briarane and asbestinane class diterpenoids (as summarized by Faulkner 1986, 1987 , 1988, 1990). Although produced by a different terpene cyclization pathway, both classes consist of bicyclic molecules with fused 6 - and 10-membered rings (see Fig. 2). The briaranes are unique in that most contain chlorine substituents; halogen substituents are thought to increase toxicities of compounds and are unique to compounds from marine organisms (Hay \& Fenical 1988). Both briaranes and asbestinanes are found only in cnidarians. A single colony can have up to 5 major and 10 minor constituents, including hydrocarbons as 
well as highly oxygenated and functionalized diterpenoids.

We surveyed the chemistry of Briareum asbestinum in the Bahamas and St. Croix, focusing on variation at both geographic and more local scales. We have concentrated on depth-related variation on local scales because this is the habitat variable most likely to affect chemistry of colonies both through variation in productivity and predator regimes. The following hypotheses about pattern and process in chemical defenses were examined: (1) shallow colonies have higher levels of secondary compounds since they occur in a higher productivity and predator regime (shallow water); (2) the qualitative differences between shallow and deep colonies are environmentally induced; and (3) secondary chemistry is homogeneous throughout the West Indies.

\section{MATERIALS AND METHODS}

The research for this paper was conducted at several sites in the Caribbean between June 1988 and August 1990. Sites in the Bahamas were Chub Cay $\left(25^{\circ} 21^{\prime} \mathrm{N}\right.$, $77^{\circ} 52^{\prime}$ W), Rum Cay $\left(24^{\circ} 20^{\prime} N, 75^{\circ} 5^{\prime}\right.$ W), Hogsty Reef $\left(21^{\circ} 41^{\prime} \mathrm{N}, 73^{\circ} 50^{\prime} \mathrm{W}\right)$, Cross Harbor $\left(26^{\circ} 25^{\prime} \mathrm{N}\right.$, $\left.77^{\circ} 51^{\prime} \mathrm{W}\right)$, and San Salvador $\left(24^{\circ} 13^{\prime} \mathrm{N}, 74^{\circ} 46^{\prime} \mathrm{W}\right)$ (Fig. 1). The other main study site was Salt River Canyon in St. Croix, US Virgin Islands (1989), the location of the NOAA Aquarius Habitat.

Samples for chemical analysis were either collected in bulk colony collections or for quantitative analysis of individual colonies. The bulk collections were assemblages of 15 to 30 colonies collected from a single site and analyzed as a single sample. This gave us a representative sample of the compounds present at a site, but did not allow us to determine degree of homogene-

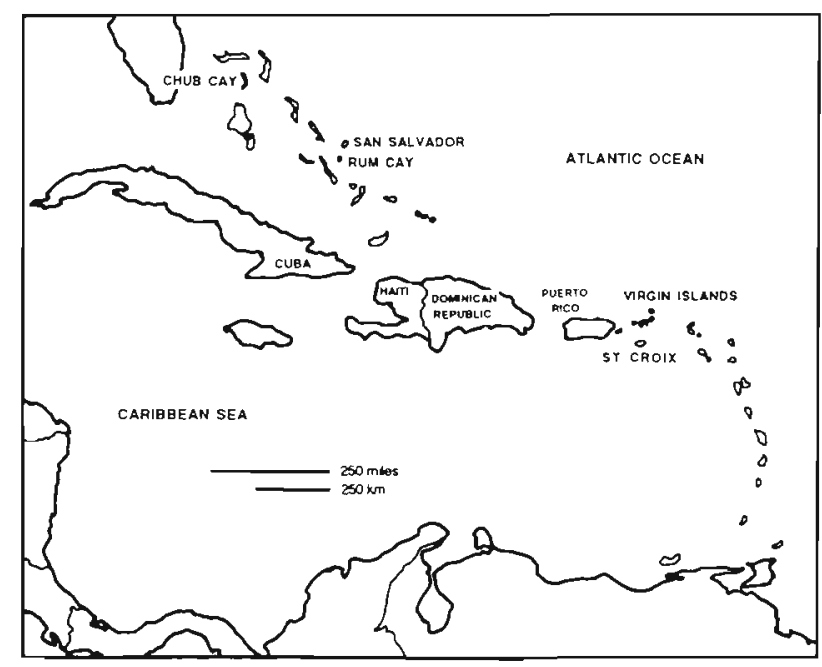

Fig. 1. Study sites in the Bahamas and Virgin Islands ity among individual colonies. To assess the degree of individual variation, we collected individual colonies from shallow and deep sites at 3 locales (Salt River Canyon, Chub Cay and San Salvador) for quantitative analysis, maximizing the potential number of genotypes included in a sample. Thus each colony from a site was separated by at least $3 \mathrm{~m}$, and came from distinctly different colony groups.

Large bulk collections of Briareum asbestinum were air-dried in the shade for $3 \mathrm{~h}$. Corals were blended with 3 separate portions of methylene chloride to produce a pigment-rich extract. Methylene chloride was selected as the extraction solvent since it was non-flammable and has been demonstrated to effectively extract the diterpenoids present. The solvent was removed under reduced pressure to yield the crude organic extracts. The bulk extracts were initially fractionated by silica gel flash chromatography (increasing proportions of ethyl acetate in isooctane) and the fractions containing diterpenoids were identified by $360 \mathrm{MHz}$ proton Nuclear Magnetic Resonance (NMR) analysis. Diterpenoids for use as standards were fully purified by silica (using ethylacetate in isooctane mixtures) and reversed phase (C-18; methanol water mixtures) High Performance Liquid Chromatography (HPLC). The structure assignments of the purified briarane and asbestinane diterpenoids were accomplished by combined spectral methods involving mainly ${ }^{1} \mathrm{H}$ and ${ }^{13} \mathrm{C}$ NMR methods. In one case, a major compound was identified as brianthein $Y$ by comparison of NMR spectral data with those appearing in the literature (Grode et al. 1983).

Both the dry weight and the volumetric yield of 4 shallow water colonies from Chub Cay were determined; only the dry weight yield was measured on deep colonies. The volume of macerated tissue for each of the shallow water colonies was measured prior to extraction. Samples were then individually extracted with methylene chloride. After at least $2 \mathrm{~d}$ of extraction, the extract was removed from the remaining tissue, filtered first through silica gel mini-flash columns and then filtered through syringe filters. Samples were quantified by silica HPLC using several eluting solvents depending upon the site of collection. The eluting solvents used were 30 to $60 \%$ ethylacetate in isooctane (Chub Cay and San Salvador) and $25 \%$ ether-isooctane (St. Croix). Both dry weights and ashfree dry weights were measured to examine the yield of terpenoids (after Harvell \& Fenical 1989). Samples were ashed at temperatures between 450 and $460^{\circ} \mathrm{C}$ and accompanied with calcium carbonate controls to ensure water of hydration was not released [see Harvell \& Fenical (1989) for more detailed methods].

Shallow and deep colonies from the Bahamas (but not St. Croix) showed distinct differences in their qual- 
Table 1. Briareum asbestinum. Variation in diterpenoids with geographic locale: shallow water colonies from the Bahamas and St. Croix, US Virgin Islands. Quantities are expressed as the percent composition of the crude extract weight. A: asbestinanes; B: briaranes

\begin{tabular}{|c|c|c|c|c|c|c|}
\hline \multirow[t]{2}{*}{ Compound } & \multicolumn{5}{|c|}{$\%$ Extract } & \multirow[b]{2}{*}{ St. Croix } \\
\hline & $\begin{array}{c}\text { San } \\
\text { Salvador }\end{array}$ & $\begin{array}{c}\text { Hogsty } \\
\text { Reef }\end{array}$ & $\begin{array}{l}\text { Acklin } \\
\text { Island }\end{array}$ & $\begin{array}{l}\text { Great } \\
\text { Abaco }\end{array}$ & $\begin{array}{c}\text { Chub } \\
\text { Cay }\end{array}$ & \\
\hline A-1 & 4.9 & 7.3 & 3.5 & 1.5 & 2.6 & 6.7 \\
\hline$A-2$ & 2.5 & 3.9 & 3.5 & 6.2 & 8.8 & - \\
\hline$A-3$ & 0.8 & 0.8 & 1.6 & 0.8 & 2.8 & - \\
\hline$A-4$ & 2.0 & 6.3 & 4.6 & 4.1 & 0.5 & 3.7 \\
\hline A-5 & - & - & - & - & - & 12.3 \\
\hline$B-1$ & 3.8 & 2.8 & 4.6 & 2.7 & 1.2 & - \\
\hline B-2 & 4.3 & 15.3 & 10.8 & 1.4 & 7.4 & - \\
\hline B-3 & 0.4 & 0.6 & 1.1 & 2.5 & 4.7 & - \\
\hline B-4 & 1.3 & 3.5 & 2.1 & - & 0.5 & - \\
\hline
\end{tabular}

itative chemistry. To determine whether individual colonies changed chemistry in different habitats, we transplanted shallow water colonies $(3 \mathrm{~m})$ to deep reefs (33 $\mathrm{m})$ at San Salvador, Bahamas. Although a reciprocal experiment would have provided even more information (West et al. in press), we were too limited in bottom time at depths of $30+m$ at a remote site for it to be feasible. Thus, the hypothesis we were testing was that the shallow water colonies would change their chemistry to match the deep colonies. One alternative hypothesis was that the shallow water colonies in deep sites would not change chemistry and would remain identical in chemistry to shallow water populations. An additional possibility is that shallow water colonies would fail to survive in deep water.

The experiment was timed to coincide with the summer growing season of Briareum asbestinum and was initiated at San Salvador on June 20, 1990 and collected on January 31, 1991. Because B. asbestinum grows at a rate of approximately 5 to $12 \mathrm{~cm} \mathrm{yr}^{-1}$ (Brazeau 1989), 7 mo seemed a sufficient time for any changes to be induced. Colonies $(10 \mathrm{~cm}$ branches $)$ were transplanted onto clear plexiglass racks, each containing 12 colonies, as in transplant experiments examining colony morphology described in West et al. (in press). The racks had 12 recessed wells $1.0 \mathrm{~cm}$ deep) to acommodate the base of the colonies and 12 padded uprights to which branches were cable-tied with 2 padded cable-ties. The transplant site was Bonefish Bay on San Salvador; all shallow colonies were collected adjacent to the transplant site. Four racks of shallow water colonies were transplanted to shallow ( $8 \mathrm{~m}$ ) water ( $\mathrm{n}=48$ colonies) and 3 racks were transplanted to a deep ( $33 \mathrm{~m}$ ) reef site ( $n=36$ colonies), also in Bonefish Bay. All the shallow water colonies died due to sand scour and some of the racks were lost due to heavy storms; 18 of 36 colonies transplanted to deep water $(33 \mathrm{~m}$ ) survived. We compare the chemistry of the 18 remaining colonies transplanted to the deep site (SD) to 9 resident deep colonies (D) and 9 resident shallow colonies (S).

The transplants were brought to the surface in January 1991 by SCUBA divers, the 0.5 to $1 \mathrm{~cm}$ tip of each colony, which was new tissue produced during the transplant interval, was preserved in dichloromethane after air-drying for $3 \mathrm{~h}$, and the remainder of each colony frozen.

Growth rate data were not recorded, but the surviving colonies were all 1 to $3 \mathrm{~cm}$ longer than the original $10 \mathrm{~cm}$ long transplants; indicating that growth did occur during the transplant interval.

\section{RESULTS}

The chemistry of colonies of Briareum asbestinum from shallow reefs is highly variable throughout regions of the Caribbean sampled (Table 1). Each sample is a composite collection of 15 to 20 colonies, and so represents a population estimate. To facilitate comparison, the major compounds, which in total comprised $75 \%$ of the diterpenoids present, were evaluated. Data presented are the proportional yields of each compound from a crude extract. These are data derived from comparing peak retention times on an HPLC. With the exception of the briarane diterpenoid brianthein Y (Grode et al. 1983), the major metabolites observed were unreported briarane, asbestinane and in one case, A-4, eunicellane diterpenoids. For the purpose of this study it was impractical to comprehensively assign the structures of all metabolites observed. Rather the major metabolites $A-1$ to $A-5$ and $B-1$ to $B-4$ were each isolated and purified, and ${ }^{2} \mathrm{H}$ and ${ }^{13} \mathrm{C} N M R$ spectra were recorded. Comparison of the NMR data obtained with those from known compounds showed 


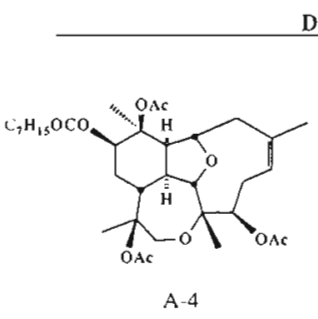

Fig. 2. Briareum asbestinum. Representative briarane-derived (B) and asbestinane-derived (A) diterpenoids from deep and shallow colonies collected at Chub Cay, Bahamas. Structure assignments are by NMR methods and are tentative

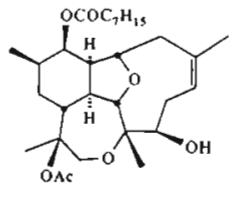

A-7
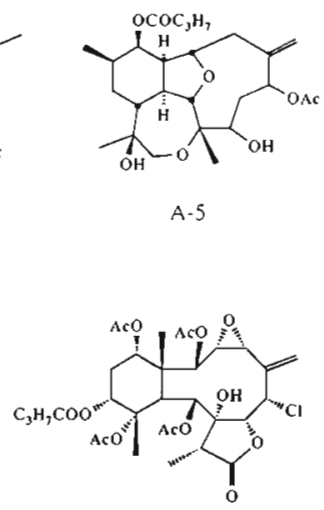

B-4

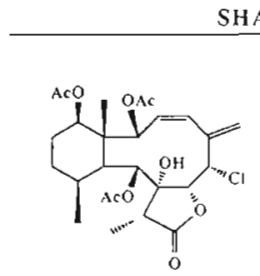

B- 1

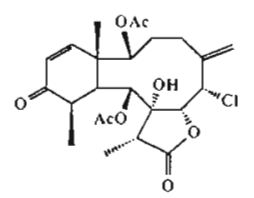

B-3

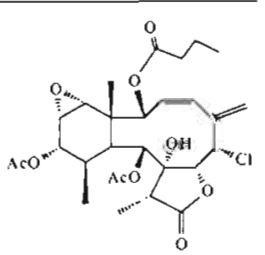

B-2 (brianthein $Y$ )

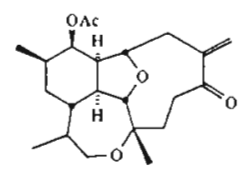

A-2 that the majority were undescribed. With the spectral data obtained (sometimes augmented with COSY and DEPT sequence data) it was possible to make the tentative structure assignments shown in Fig. 2. Purified diterpenoids were used as HPLC standards to derive the data presented in Table 1 . The purpose of the table is to display the large qualitative variation that we detected among geographic locales in 1 analysis. Colonies from the Bahamas show minor qualitative variation (differential presence or absence of compounds) among different islands but overlap very little in compounds with colonies from St. Croix. St. Croix gorgonians have a lower diversity of shallow water compounds than colonies from the Bahamas (Table 1), and are composed of mainly asbestinane diterpenoids instead of a mix of briaranes and asbestinanes.

Colonies also vary in composition on a more local scale at some sites in the Bahamas where colonies from shallow water have largely different compounds than those from deeper reefs. In Chub Cay, individual colo-

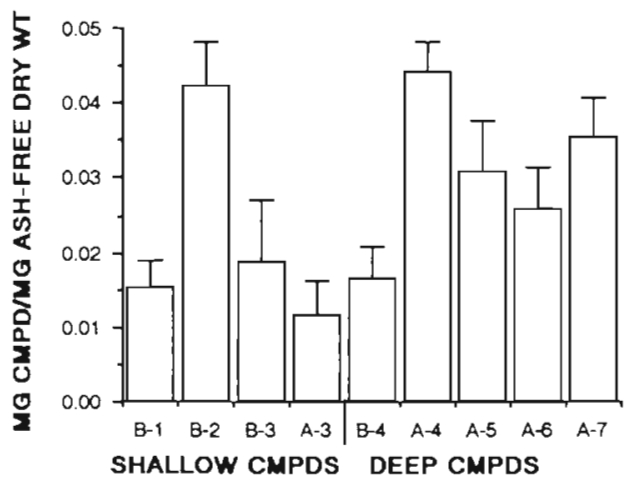

Fig. 3. Briareum asbestinum. Quantitative analysis of the major briaranes (B-) and asbestinanes (A-) from shallow $(n=4)$ and deep ( $n=5$ ) colonies from Chub Cay, Bahamas. The proportion of pure compound (CMPD) is expressed per ash-free dry weight Mean $+1 \mathrm{SE}$ is shown nies were quantitatively sampled and NMR spectral data used to uniquely identify compounds, revealing a qualitative and quantitative homogeneity in chemistry among individuals from a particular depth (Fig. 3).

The chemistry of the deep colonies at Chub Cay was not only qualitatively distinct from the shallow colonies but also contained a higher proportion of compounds, quantified for the major diterpenoids as the compound weight per ash-free dry weight (Fig. 3). The total summed briaranes and asbestinanes are higher in deep water $(0.152 \pm 0.174)$ than shallow water colonies $(0.086 \pm 2.08$; unpaired $t$-test, $t=2.432, p=0.05)$. The ash-free dry weight excludes the weight of the sclerites. The volumetric yield (mean $\pm \mathrm{SE}$ ) of the same shallow water Chub Cay colonies was $41.62 \pm 6.44 \mathrm{mg}$ $\mathrm{ml}^{-1}$.

In St. Croix, where individual colonies were also quantitatively sampled, the pattern of variation in chemistry with depth was different. The diterpene compositions of shallow and deep colonies were qualitatively similar, although as in Chub Cay, the deeper colonies contained a higher concentration of each of the 3 asbestinanes (Fig. 4, A-1: $t=5.274, p=0.001$; $\mathrm{A}-4: t=3.674, \mathrm{p}=0.0013 ; \mathrm{A}-5: t=2.896, \mathrm{p}=0.0083)$. The proportions were arc-sin transformed, differences between the concentrations of the 3 compounds between shallow and deep colonies compared with t-tests, then back-transformed for display in Fig. 4. Because 3 variables were considered, we adjusted the comparisonwise alpha to $0.05 \div 3=0.017$. All comparisons were still significant at this level. The proportion of sclerites also varied significantly between shallow and deep colonies; in shallow colonies the proportion was $0.812 \pm 0.019$ ) and in deep colonies $0.871 \pm 0.012$ ) ( $\mathrm{p}<0.0153$, unpaired $t$-test). Thus deeper colonies have both higher levels of compounds and a higher complement of sclerites.

To examine whether the differences between shal- 

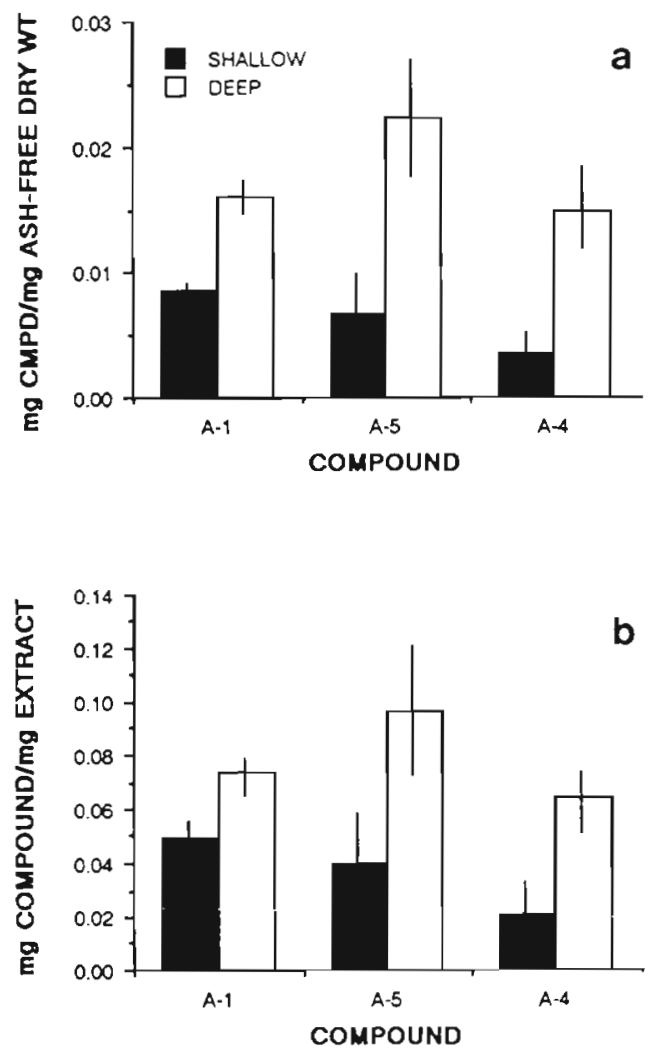

Fig. 4. Briareum asbestinum. Quantitative analysis of the 3 major compounds (asbestinanes) from coral sampled on shallow $(10 \mathrm{~m} ; \mathrm{n}=16)$ and deep $(33 \mathrm{~m} ; \mathrm{n}=18)$ reefs at St. Croix, US Virgin Islands. The proportion of pure compound is expressed as (a) per ash-free dry weight and (b) per total extract weight. Back-transformed mean $\pm 1 \mathrm{SE}$ plotted.

The concentrations of all 3 compounds are significantly greater (unpaired $t$-test, $p<0.016$ ) in deeper water

low and deep water colonies in the Bahamas were environmentally induced, we transplanted shallow colonies to deep water in San Salvador. Colonies that had been transplanted to deep reefs for 7 mo (SD) retained the characteristic shallow water chemistry. TLC analysis revealed that $10 \mathrm{SD}$ colonies sampled showed the same chromatographic pattern as $10 \mathrm{~S}$ colonies sampled and appeared different from $10 \mathrm{D}$ colonies sampled. Because TLC can be unreliable in visualizing the briarane and asbestinane compounds, we also analyzed the transplants with HPLC. Using 4 standards isolated from and charactersitic of the shallow water form, we compared the retention times of the standards and quantified the percent yield of each of 4 shallow water diterpenes in the transplants. HPLC analysis of the $18 \mathrm{SD}$ colonies revealed that all had the distinctive shallow water chemistry (they still contained Brianthein $Y$ and $B-5$ ), and were qualitatively similar to 9 shallow water colonies and distinct from 9 deep water colonies. Thus the shallow colonies, even in a deep environment, did not lose their characteristic shallow water chemistry (Fig. 5).

There were some consistent quantitative differences in the chemistry between resident shallow colonies and shallow colonies transplanted deep in the Bahamas that suggest environmental modulation of secondary chemistry (Fig. 5). Since we were not able to compare the SD transplants to control colonies transplanted in shallow water, we cannot rule out the possibility that the greater levels of compounds in the transplanted deep colonies is due to some experimental artefact. The transplanted colonies had higher levels of most compounds than the shallow colonies. With an adjusted alpha of $0.05 \div$ by $4=0.012$, unpaired $t$-tests still show significant differences between shallow and deep colonies for some compounds as a function of dry weight (B-5: $p=0.285 ; \mathrm{Br}-\mathrm{Y}: \mathrm{p}=0.007$; $\mathrm{A}-8$ : $p=0.296 ;$ A-9: $p=0.029 ;$ summed compounds: $p=0.011)$ and extract weight $(B-5: p=0.875 ; \mathrm{Br}-\mathrm{Y}$ : $\mathrm{p}=0.025 ; \mathrm{A}-8: \mathrm{p}=0.02 ; \mathrm{A}-9: \mathrm{p}=0.018$; compounds summed: $p=0.08$ ). Asterisks on Fig. 5 indicate compounds that are significantly different at the comparisonwise alpha of 0.01 .
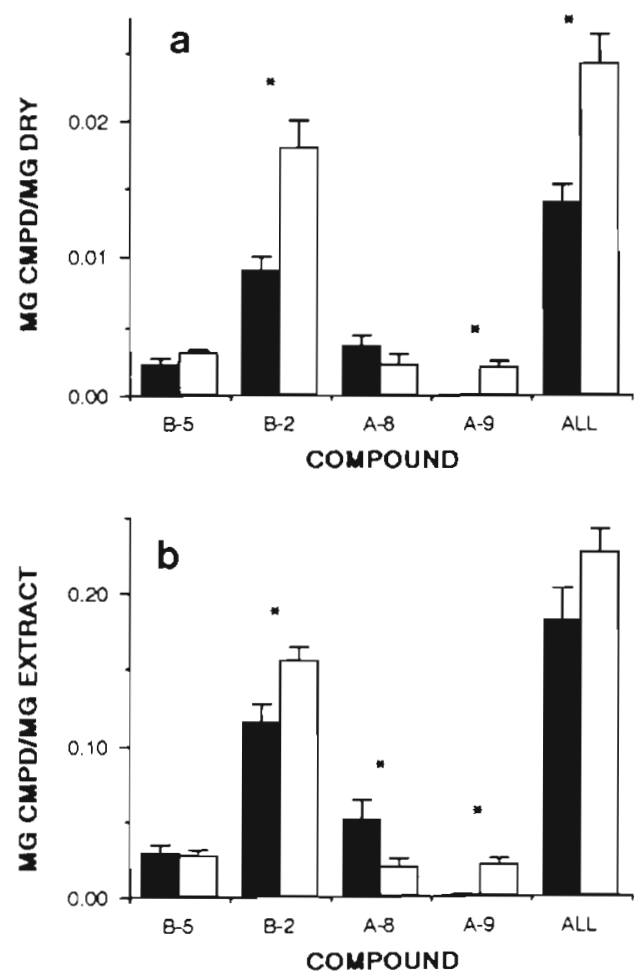

Fig. 5. Results of transplant experiment in San Salvador, Bahamas. Composition of resident shallow colonies $(S$, $\mathrm{n}=9$ ) and colonies transplanted from shallow to deep (SD, $\square$ : $\mathrm{n}=18$ ) water. The proportion of pure compound is expressed as (a) per ash-free dry weight and (b) per total extract weight. Mean +1 SE plotted. Asterisks indicate compounds that vary significantly (at a comparisonwise alpha of 0.01 ) between shallow and deep reefs 


\section{DISCUSSION}

The extent of variation in the secondary compounds of Briareum asbestinum among habitats is pronounced. Although compounds may vary quantitatively among individuals and habitats in other species, the type of hypervariability seen in $B$. asbestinum is not usual for other species of gorgonians investigated, particularly over such small spatial scales as observed in the Bahamas for the variation of secondary compounds with depth (W.F. pers. obs.). Recent studies extend our analysis of chemical variability for this species by reporting yet another new class of compounds (briareolides) in Briareum asbestinum from Puerto Rico (Pordesimo et al. 1991). This type of habitat-specific variation within a species can be caused by either fixed genetic differences between populations or by environmentally-induced changes in different habitats. Our transplant experiment suggests that adult colonies do not change chemistry qualitatively to match their habitat. The transplant experiment also shows evidence for quantitative induction; diterpene concentrations increased in translocated colonies moved to deep reefs, thus producing the characteristic pattern of higher levels of secondary compounds in deeper water. The observation that colonies changed quantitatively further suggests that the 7 mo transplant interval was sufficient for an environmental change to occur.

The genetic population structure of Briareum asbestinum from Bonefish Bay in San Salvador, Bahamas is highly subdivided (D. A. Brazeau \& C.D.H. unpubl.). The shallow and deep populations varied significantly in the frequencies of alleles at 5 loci sampled. Even adjacent subpopulations in shallow water showed significant differences in allele frequencies. However, the magnitude of the variation is well within that expected for a single species. Similarly, the values for Nei's genetic distance support the notion that these are isolated populations of the same species. These results are expected considering the very localized dispersal expected from larvae and sperm of $B$. asbestinum (Brazeau \& Lasker in press). The combination of evidence demonstrating highly subdivided genetic structure in populations of Briareum asbestinum and stable chemotypes lends support to the hypothesis that the chemical variation is due to localized genetic adaptation.

The function of these secondary compounds and the major selective agents in contemporary communities are still unknown. One hypothesis for the function of briarane and asbestinane diterpenes is as a deterrent to consumers. Our experiments confirm that the extracts and pure compounds of both shallow and deep colonies do function effectively as deterrents to gener- alized fish predators both in the field and in the lab (C.D.H. \& W.F. unpubl.). These same compounds are not effective deterrents against some invertebrate predators such as a trophically specialized mollusc, Cyphoma gibbosum (C.D.H. \& W.F. unpubl.). The presence of high concentrations of diterpenes in all developmental stages, the oocytes, embryos, larvae and juveniles (C.D.H., J.M. \& W.F. unpubl.) and the unpalatability of these stages further emphasizes a defensive function for the asbestinanes and briaranes. The developmental stages are brick orange and, unlike in any other coral in the Caribbean, are brooded on the surface of the colony. The combination of deterrence of the compounds to fish and the unpalatability of the chemically endowed developmental stages implicates these compounds as defenses against vertebrate predators

The function of the depth-related variation in secondary compounds remains a mystery. Both vertebrate and invertebrate predators are more abundant on shallow reefs than deep reefs (C.D.H. \& W.F. unpubl.). The ability to fix carbon from autotrophic sources is likely to be compromised on deep reefs due to reduced light for the symbiotic zooxanthellae (Davies 1980, McCloskey \& Muscatine 1984, Muscatine 1990). Briareum asbestinum from deep reefs in St. Croix contain zooxanthellae and appear to be primarily autotrophic (J. Miles \& C.D.H. unpubl.). The simplest prediction based on ecological patterns and on energetic grounds would be that colonies in shallow water should have a greater allocation to defense because the productivity rate, the numbers of predators and the amount of wounding by predators is higher (C.D.H. \& W.F. unpubl.). Our data are not consistent with this prediction, however, since we find that deeper colonies have higher levels of diterpenes. Greater defense is sometimes predicted in lower resource environments, because the cost of replacing lost tissue is so high when productivity is low (Coley et al. 1985). In plants, theories to explain the relationship between levels of carbon-based secondary compounds and productivity rely on relative amounts of carbon and other nutrients (Bryant et al. 1983, Price et al. 1989). Since gorgonians are analogous to plants in also being primary producers and generating carbohydrates, the predictions from this theory might apply. The hypothesis developed by Bryant predicts that a balance exists between concentrations of nutrients such as nitrogen and phosphorous and carbohydrate concentrations. The carbohydrates contribute the carbon skeleton to carbon-based defenses and the nutrients are directly used in organism growth. Under some growth conditions, there is surplus carbohydrate that can go to carbon-based secondary compounds. It is not known how carbohydrate availability scales with growth rate in corals so it is dif- 
ficult to evaluate the applicability of carbon-nutrient balance theory to explain allocation to chemical defense in corals. It is possible that on deeper reefs the growth rates of colonies may be disproportionately slowed, thus generating a surplus of carbohydrate for secondary compounds.

This study is the first attempt to examine spatial variation in secondary defensive compounds of any colonial invertebrate and raises a number of questions about spatial variation and the evolution of chemical defenses in tropical marine corals. We have provided evidence that the qualitative difference in secondary chemistry between shallow and deep reefs is highly localized spatially and fixed in adult colonies, and that there is some environmental modulation of levels of defenses in transplanted colonies. In addition, diterpenes of Briareum asbestinum vary dramatically in different geographic regions of the Caribbean. Although we have little information yet about the potential adaptive nature of such variation, it could be a response to variation in selection by consumers and pathogens. Chemical defenses of some plants are notoriously quantitatively variable in response to herbivore attacks, both temporally (Carroll \& Hoffman 1980) and spatially (Jones 1966, Sturgeon 1979). Hypervariability in secondary compounds in different populations of $B$. asbestinum and modulation of levels of existing compounds may be an adaptation to shifting biotic or abiotic regimes, permitting the wide habitat range occupied by this species.

Acknowledgements. This project was funded by NOAA through the Aquarius Program (NURC) in St. Croix, USVI, by NSF Grant OCE-9012034 to C.D.H., and by NSF Grants CHE86-20217 and CHE90-08621 to W.F. We are grateful for diving assistance in the field from J. Nowlis, J. West, B. Helmuth, C. Lennert, and A. Sewell and for statistical assistance from L. Buttel. We also owe thanks to the entire Aquarius crew for their assistance during our NOAA mission, particularly to Doug Kesling for help with diving and especially with underwater video technology. We also appreciate the use of laboratory facilities at West Indies Laboratory and the Bahamian Field Station (San Salvador) and for ship support from NSF (through CHE 86-20217 to W.F.) which funded use of the RV 'Columbus Iselin'

\section{LITERATURE CITED}

Antonovics, J. (1976). The nature of limits to natural selection. Ann. Mo bot. Gard. 63: 224-247

Bakus, G. J., Targett, N. M., Schulte, B. (1986). Chemical ecology of marine organisms: an overview. J. chem. Ecol. 12: 951-987

Bandurraga, M. M. Fenical, W. (1984). Evidence of a chemical adaptation against fouling in the marine octocoral Muricea fruticasa (gorgonacea). Tetrahedron 41: $1057-1065$
Bayer, F. M. (1961). The Shallow Water Octocorallia of the West Indian Region. Nijhoff, The Hague

Brazeau, D. A. (1989). A male-biased sex ratio in the Caribbean Octocoral, Briareum asbestinum: sex ratio evolution in clonal organisms. Ph.D. dissertation, State Univ. of New York, Buffalo

Brazeau, D. A., Lasker, H. R. (1990). Sexual reproduction and external brooding by the Caribbean gorgonian Briareum asbestinum. Mar. Biol. 104: 465-474

Brazeau, D. A. , Lasker, H. R. (in press). Reproductive success in a marine benthic invertebrate, the Caribbean octocoral Briareum asbestinum. Mar. Biol.

Bryant, J. P., Chapin, F.S., Klein, D. R. (1983). Carbon/nutrient balance of boreal plants in relation to vertebrate herbivory. Oikos 40: $357-368$

Carroll, D. R., Hoffmann, C. A. (1980). Chemical feeding deterrent mobilized in response to insect herbivory and counter-adaptation by Epilachna tredecimnotata. Science 209: $414-416$

Coley, P. D., Bryant, J. P., Chapin, F. S. III (1985). Resource availability and plant anti-herbivore defense. Science 230 895-899

Davies, P. S. (1980). Respiration in some Atlantic reef corals in relation to vertical distribution and growth form. Biol. Bull. 158: $187-194$

Faulkner, D. J. (1986). Marine natural products. Nat. Prod. Rep. 3: 1-86

Faulkner, D. J. (1987). Marine natural products. Nat. Prod. Rep. 4: $473-550$

Faulkner, D. J. (1988). Marine natural products. Nat. Prod. Rep. 5: 541-663

Faulkner, D. J. (1990). Marine natural products. Nat. Prod Rep. 7: 269-309

Fenical, W. (1982). Natural products chemistry in the marine environment. Science 215: 923-928

Gerhart, D. J. (1984). Prostaglandin A2: an agent of chemical defense in the Caribbean gorgonian Plexaura homomalla. Mar. Ecol. Prog. Ser. 19: 181-187

Grode, S. H., James, T. R. Jr, Cardellina, T. H. II, Onan, K. D. (1983). Molecular structure of the Briantheins, new insecticidal diterpenes from Briareum polyanthes. J. org. Chem. 48: 5203-5207

Harper, J. L. (1981). The concept of population in modular organisms. In: May, R. M. (ed.) Theoretical ecology: principles and applications. Sinauer Assoc., Sunderland, MA

Harvell, C. D., Fenical, W. (1989). Chemical and structural defenses of Caribbean gorgonians (Pseudopterogorgia spp.). II. Intracolony localization of defense. Limnol. Oceanogr. 34: 382-389

Harvell, C. D., Fenical, W., Greene, C. H. (1988). Chemical and structural defenses of Caribbean gorgonians (Pseudopterogorgia spp.). I. Development of an in situ feeding assay. Mar. Ecol. Prog. Ser. 49: 287-294

Harvell, C. D., Suchanek, T. H. (1987). Partial predation on tropical gorgonians by Cyphoma gibbosum (Gastropoda) Mar. Ecol. Prog. Ser. 38: 37-44

Hay, M. E., Fenical, W. (1988). Marine plant-herbivore interactions: the ecology of chemical defense. A. Rev. Ecol Syst. 19: 111-145

Jones, D. A. (1966). On the polymorphism of cyanogenesis in Lotus corniculatus. Can. J. Genet. Cytol. 8: 556-567

Jones, D. A. (1972). Cyanogenic glycosides and their function. In: Harbome, J. B. (ed.) Phytochemical ecology. Academic Press, London

LaBarre, S. C., Coll, J. C. Sammarco, P. W. (1986). Competitive strategies of soft corals (Coelenterata: Octocorallia): 
III. Spacing and aggressive interactions among alcyonaceans. Mar. Ecol. Prog. Ser. 28: 147-156

Lasker, H. R. (1983). Vegetative reproduction in the octocoral Briareum asbestinum. J. exp. mar. Biol. Ecol. 72: 157-169

Lasker, H. R. (1985). Prey preferences and browsing pressure of the butterflyfish Chaetodon capistratus on Carribean gorgonians. Mar. Ecol. Prog. Ser. 21: 213-220

Look, S. A., Fenical, W., Van Engen, D., Clardy, J. (1984). Erythrolides: unique marine diterpenoids inter-related by a naturally occurring di-pi-methane arrangement. J. Am. Chem. Soc. 106: 5026

McCloskey, L. R., Muscatine, L. (1984). Production and respiration in the Red Sea coral Stylophora pistillata as a function of depth. Proc. R. Soc. Ser. B 222: 215-230

Muscatine, L. (1990). Ecosystems of the World: Coral Reefs 25: $75-87$

Pawlik, J. R., Burch, M. T., Fenical, W. (1987). Patterns of chemical defense among Caribbean gorgonian corals: a preliminary survey. J. exp. mar. Biol. Ecol. 108: 55-66

Paul, V. J., Van Alstyne, K. L. (1988). Chemical defense and chemical variation in some tropical Pacific species of Halimeda (Halimedaceae; Chlorophyta). Coral Reefs 6: $263-269$

Pordesimo, E. O., Schmitz, F. J., Ciereszko, L. S., Hossan, M. B., van der Helm, D. (1991). J. org. Chem. 56: 2344-2357

Price, P. W., Waring, G. L., Julkunen-Tiitto, R., Thavanainen, J., Mooney, H. A., Craig, T P. (1989). Carbo-nutrient bal-

This article was submitted to the editor ance hypothesis in within-species phytochemical variation of Salix lasiolepis. J. chem. Ecol. 15: 1117-1131

Rittschoff, D., Hooper, I. R., Branscomb, E. S., Costlow, J. D. (1985). Inhibition of barnacle settlement and behavior by natural products from whip corals, Leptogorgia virgulata. J. chem. Ecol. 11: 551-563

Sammarco, P. W., Coll, J. C, LaBarre, S. C., Willis, B. (1983). Competitive strategies of soft corals (Coelenterata: Octocorallia): allelopathic effects on selected scleractinian corals. Coral Reefs 1: 173-178

Sammarco, P. W., LaBarre, S., Coll, J. C. (1987). Defensive strategies of soft corals (Coelenterata: Octocorallia). III The relationship between ichthyotoxicity and morphology. Oecologia 74: 93-101

Sturgeon, K. B. (1979). Monoterpene variation in ponderosa pine xylem resin related to western pine beetle predation. Evolution 33: 803-814

Targett, N. M., Bishop, S. S., McConnell, O. J., Yoder, J. A. (1983). Antifouling agents against the benthic diatom, Navicola salinicola. J. chem. Ecol. 9: 817-829

Tursch, B., Braekman, D., Daloze, D., Kaisin, M. (1978). Terpenoids from coelenterates. In: Scheuer, P. J. (ed.) Marine natural products. Chemical and biological perspectives, Vol. II. Academic Press, New York, p. 247-296

West, J M., Harvell, C. D., Walls, A. M. (in press). Morphological plasticity in a gorgonian coral (Briareum asbestinum) over a depth cline. Mar Ecol. Prog. Ser.

Manuscript first received: May 27, 1992

Revised version accepted: December 17, 1992 